\title{
Engagement Strategies for E-commerce Businesses in the Modern Online World
}

https://doi.org/10.21272/sec.5(4).24-34.2021

Jenjira Phomkamin, ORCID ID: https://orcid.org/0000-0001-6282-2235

Ramkhamheang University, Institute of International Studies, Thailand

Chalita Pumpuang, ORCID ID: https://orcid.org/0000-0003-4358-5427

Ramkhamheang University,Institute of International Studies, Thailand

Pattarawan Potijak, ORCID ID: https://orcid.org/0000-0003-0557-4380

Ramkhamheang University, Institute of International Studies, Thailand

Supaporn Sangngam, ORCID ID: https://orcid.org/0000-0002-3071-7323

Ramkhamheang University, Institute of International Studies, Thailand

Issariya Ketprasit, ORCID ID: https://orcid.org/0000-0003-1268-7877

Ramkhamheang University, Institute of International Studies, Thailand

Bahaudin G. Mujtaba, D.B.A., ORCID ID: https://orcid.org/0000-0003-1615-3100

Nova Southeastern University, Huizenga College of Business \& Entrepreneurship, USA

\begin{abstract}
The engagement of customers on websites should be at the heart of e-commerce because driving traffic to a website or platform enhances the opportunity for better branding and growth in revenues. Through a review of literature and practical observations of various websites, this paper explains engagement for e-commerce to increase traffic on websites and its benefits to companies. For this reason, we have summarized several important factors of success in e-commerce and the trends of consumer behavior in visiting websites. The results of this research are the accumulation of fundamental strategies and recommendations to enhance e-commerce business in the modern workplace.

Electronic commerce (e-commerce) is a growing business that will most certainly continue to grow in the future. We are amid the continued growth of e-commerce, which indicates that the e-commerce business has become more competitive. It is mandatory to expand engagement for companies to attract customers, to retain them, and to increase sales as much as possible in an ethical and sustainable manner. A website or platform with more traffic means more opportunities to sell products or services accordingly. Due to the current economy being hurt by the Covid-19 coronavirus infection and quarantine restrictions, and the daily use of social media, consumers are changing their behavior to access more information in the online world, particularly through engaging and attractive websites. As such, relevant suggestions and recommendations are offered throughout this paper to create awareness regarding the importance of customer engagement in c-commerce.
\end{abstract}

Keywords: e-commerce, electronic commerce, engagement strategies, phishing, vishing, spoofing, website.

JEL Classification: F10. 
SocioEconomic Challenges, Volume 5, Issue 4, 2021 ISSN (print) - 2520-6621, ISSN (online) - 2520-6214

Cite as: Jenjira Phomkamin, Chalita Pumpuang, Pattarawan Potijak, Supaporn Sangngam, Issariya Ketprasit, Bahaudin G. Mujtaba (2021). Engagement Strategies for E-commerce Businesses in the Modern Online World. SocioEconomic Challenges, 5(4), 24-34. https://doi.org/10.21272/sec.5(4).24-34.2021.
Received: 03.09 .2021
Accepted: 15.10 .2021
Published: 16.12.2021

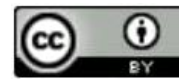

Copyright: (C) 2021 by the authors. Licensee Sumy State University, Ukraine. This article is an open access article distributed under the terms and conditions of the Creative Commons Attribution (CC BY) license (https://creativecommons.org/licenses/by/4.0/).

\section{Introduction}

E-commerce refers to the process of buying or selling products or services over the internet locally, nationally, or internationally (Kutz, 2016; Wayman, 2018), and such activities took centerstage during the Covid-19 coronavirus pandemic and quarantine periods in 2020 and 2021. As such, online shopping has now become the norm for many consumers and it is becoming increasingly more popular because of speed, ease of its use for customers and overall convenience.

While the web is for small, medium-size, and large organizations, small businesses that are considering purchasing or selling online should make good use of modern technology (as they rely on a limited budget). E-commerce activities such as selling online can be directed at consumers or other businesses. Business to Consumer (B2C) involves the online sales of goods, services, and provision of information directly to consumers. Business to Business $(B 2 B)$ refers to the online selling of products, services, or information between businesses. Selling online can help your business reach new markets and increase your sales and revenues. If you are interested in selling to other businesses, you can use the Internet to find sales leads, announce calls for tender and offer products for sale either through your own website or through an e-marketplace site (Authorize.net, 2012; Bessemer e-commerce laws, 2010; Ontario ecommerce, 2013; Schneider, 2013; Shim, 2010).

There are many benefits to e-commerce. For example, using e-commerce, you can be leveraging your existing web presence. If you already have B2C operations, you can extend them to business clientele - perhaps by providing private areas for special pricing, delivery options, etc. However, this additional functionality is not trivial and could require rebuilding your online store at a significant cost. You can have better customer service as nowadays businesses can deal directly with their customers 24/7. As such, one benefit of e-commerce and having a website is the elimination of intermediaries. Businesses, particularly manufacturers, can offer lower and more affordable goods to consumers by selling products directly, thereby eliminating distributors and retailers that add to the cost of the products. Even if you have a small business with low budget, your e-commerce site can enhance your reputation by projecting a larger picture and allowing you to compete on a level playing field (Kutz, 2016; Wayman, 2018; Watson, Berthon, Pitt, and Zinkhan, 2008).

Of course, security is always a concern in any online or e-commerce activity. While technology can make our lives easier, there are going to be unintended consequences (such as cyber security breaches) that need to be studied, researched, and taken care of in a positive manner. As such, it is important to be aware of security and privacy issues associated with e-commerce. Some common security threats include fraudulent use of credit cards, computer viruses, spam (unsolicited e-mail messages), phishing, vishing, whaling, and theft of computers or information. Phishing is a type of security threat that involves an e-mail message that appears or looks like it is coming from an official source, but links in the message go to a fake website where you may end up disclosing personal information to swindlers and imposters (KnowBe4.com, 2021; MalwareFox, 2020). Common threats to privacy include theft of personal information and inadequate protection of private information (Ontario ecommerce, 2013; Authorize.net, 2012; Bessemer e-commerce laws, 2010).

Voice phishing, or vishing, is the use of telephony (often Voice over IP telephony) to conduct phishing attacks. Vishing fraudsters often use modern Voice over IP (VoIP) features such as caller ID spoofing and automated systems to impede detection by law enforcement agencies. Voice phishing is typically used to steal credit card numbers or other information used in identity theft schemes from individuals. As defined by most experts, vishing 
is the fraudulent or illegal practice of making phone calls or leaving voice messages claiming to be from reputable individuals or companies in order to induce people to reveal personal information, such as bank details, identification numbers, and/or credit card numbers. These attacks try to trick an employee into giving out confidential information via a phone call. Vishing is a type of social engineering.

Social engineering is the art of manipulating, influencing, or deceiving a person in order to gain control over his/her computer system and organizational networks. Here, the hacker might use the phone, email, snail mail or direct contact to gain illegal access. Social engineering attacks can include phishing, spear phishing, executive fraud, ransomware, etc. Of course, phishing, spear phishing, and whaling are types of cyber-attacks that are based on social engineering methods. The hacker tricks users in believing that they represent a reputable organization, government officials, senior, or a person that they knew. Then they steal confidential information using the fake website or by installing spyware on their personal computer or organizational network system.

Spoofing is imitating (something) while exaggerating its characteristic features for comic effect. In the modern cyberspace workplace, it is a hoax or trick on someone to get them to divulge information that is private to the organization. With spoofing, hackers and attackers of all types imitate people, companies and even computers with the intent to trick people into giving up personal information in order to gain access to something valuable. Spoofing happens when cybercriminals use deception to appear as another person or source of information. The reality is that criminal can manipulate today's technology, such as email services and messages, or the underlying protocols that run the internet. Attackers target people and/or things for some form of profit. It should be noted that spoofing usually involves some type of pretext followed by an action statement.

E-commerce business owner should be aware of the Secure Socket Layer (SSL), which is the most commonly used technology for secure online transactions. This is important to keep data secure and to build trust with current and prospective consumers. Basically, SSL encrypts (or codes) all data between the shop's server and the customer's computer. This makes it very difficult for third parties to decode any information exchanged such as credit card numbers. The goal is to engage people through your e-commerce business or company website in a secure manner and without being a victim of modern hackers.

Regardless of the challenges that managers and organizations face nowadays, we cannot deny the fact that ecommerce and company websites make it easier for consumers to find information, products, and services. In addition, instead of going to a retail store, millions of people nowadays shop online using both traditional and ecommerce methodologies.

\section{Methodology}

When online marketing channels first appeared, the cost of marketing products or services was often prohibitively expensive and difficult to measure. Consider national television ad campaigns, which are evaluated using consumer focus groups to determine levels of brand awareness. These methods are also traditionally unsuitable for controlled experimentation. Traditional television viewership has been falling among most major demographics between the ages of 2 and 49 (Business Insider, 2017). The use of the internet and social media has changed consumer behavior, and the way businesses operate. Organizations can benefit from social and digital marketing by lowering costs, increasing brand awareness, and increasing sales (Ajina, 2019). Facebook pages have over 50 million registered businesses, and more than 88 percent of businesses use Twitter for marketing (Lister, 2017). Digital and social media technologies and applications have also been widely used to raise public awareness of government services and political campaigns (Grover, 2019).

The methodology of this paper is made up of literature review, observations of best practices from the experiences of the authors with online websites and summarizing of several essential strategies to effectively engage online consumers in modern businesses. Overall, this article brings together the collective wisdom of several leading experts on digital and social media marketing issues to engage e-commerce consumers through a firm's website. The perspectives of the experts provide a detailed narrative on critical aspects of this crucial topic as well as viewpoints on more specific issues such as Responsive Website, Video Content Marketing, Native advertising, Social Commerce, Email Marketing, Guest blogging, SEO, Word of mouth, Influencer Marketing, Attracting Customers by Rewards, and Podcasts Creating. 


\section{Findings for engagement}

\section{Responsive Website}

A responsive website is a concept that argues that design and development should adapt to the user's behavior and environment, considering the screen size, platform, and orientation. Nowadays, the user's journey across the internet is complicated. People access the internet via smartphones, tablets, laptops, desktop computers, televisions, and even smartwatches. Based on several page-loading tests, delays can substantially impact user experience and cause them to quit and never return. These outcomes apply to both familiar and unfamiliar pages. Websites with responsive design are easier to interact with, share, and link to, making them more user-friendly. Furthermore, having a top-notch mobile-friendly website and a great user experience would encourage visitors to return and provide more reasons to remain. About 59.9 percent of South Korean web users had purchased something via a mobile device and 55.4 percent for global customers (Chevalier, 2021).

Most internet shoppers use a mobile device for shopping. Responsive websites will not only increase sales, but it will also make your website more accessible, attracting even more potential customers. "Daily Social Media Usage Worldwide 2012-2020" reported that people now spend 145 minutes a day on social media, up from 142 minutes the previous year (Statista Research Department, 2021). Much of this browsing is completed on mobile phones. As a result, a slow website might lose not just new clients but also existing ones. We must ensure that our website looks nice on screens of various shapes and sizes to deliver the best user experience.

\section{Video Content Marketing}

The principles of video content marketing are to create and distribute valuable and consistent video content to your target audience to attract, engage, and convert qualified prospects. One form of content marketing that can increase website traffic is video marketing. Video marketing can be a vital tool for disseminating its message to a big audience in an easily digestible format. Video marketing can be used for both business-to-customer and business-to-business transactions. Cisco Visual Networking Index' reported video streaming and downloads are expected to account for 82 percent of global internet traffic by 2022. Nowadays, video streaming has increased traffic to 86 percent of video marketers' websites, and 41 percent of video marketing used in business has increased since 2016. In 2021, from the WYZowl report, 87 percent of businesses used video as a marketing tool. Consequently, if you want your website to be attractive to users and not be inferior to other websites, you need to add video content because 54 percent of users love seeing video content of a business or brand they advocate (Mohsin, 2020). The "stickiness" measures will increase as users will stay long on an engaging website if they identify what it performs and how it can benefit them.

\section{Native advertising}

Native advertising is advertising that is formatted as regular content. Native advertising is created to resemble non-advertising to integrate the content of the advertising with the audience's interests. The audience may not realize they are viewing commercial content until they have finished seeing them. The working principle of native advertising is to attach products in appropriate amounts to make content noticeable and valuable. It is considered to require both scientific and artistic expertise in its implementation. As the IAB Native Task Force has indicated, six categories of native advertising are frequently utilized to accomplish the strategy: Paid Search, In-Feed, Widgets, Promoted Listings, In-Ad, and Custom. The statistics in 2019 demonstrated native advertising was rising in popularity and effectiveness. As compared to traditional display advertising, Native Display Advertising has an 8x higher CTR (Click-Through-Rate) or click-per-100-view rate than traditional display advertising. Native advertising increased a 9 percent greater brand affinity and an 18 percent greater purchase intent than display ads. Native advertising gets 53 percent more views than traditional display ads. Pet, food \& drink, and family \& parenting categories have CTRs of 1 percent or higher delivered by native advertisements. Branded content is trusted by two out of three Generation $\mathrm{X}$ and $\mathrm{Z}$ consumers more than traditional advertising. Native advertisements have a 40x greater CTR than conventional display ads. 


\section{Social Commerce}

"Social commerce" refers to a customer's whole purchase process occurring on a social media platform. It can also mean following links on social media to a retailer's product website with an instant buying option. Most customers use social media and are required to chase through social media platforms. Therefore, implementing a social commerce solution that engages people and converts their social media participation straight into sales is more innovative. The most important point is making it easy for users to complete their purchase to remove obscurity and abandonment. Social distancing and stay-at-home orders during the coronavirus pandemic increased the popularity of e-commerce rapidly. The surge in e-commerce paired with the 16.4 percent year-over-year increase in social media usage - Millennials and Gen Zers, who are familiar with and influenced by influencer content, are inclined to engage more often with social media. Internet users tend to shop online and use social media to research brands. According to a GWI poll (2020), 76.8 percent of worldwide internet users purchased a product online in 2020, and 44.8 percent utilized social media to research brand-related information. Social media channels tend to acquire more and more users. To enhance the engagement of users on websites, it is necessary to rely on social media channels. Andrew Lipsman (2020, para. 5) claimed: "social media platforms that are most effective at driving social commerce are Instagram and Pinterest which provide the most relevant social commerce experiences for brands today, but Facebook, Snapchat, and TikTok are all expanding their offerings." These brands like Facebook, Snapchat, and TikTok are starting to benchmark or follow some of Instagrams' and Pinterests' steps and best practices in creating influential driving factors for social commerce.

\section{Email Marketing}

Ray Tomlinson sent the first email in 1971. It was sent from one computer to another via a subnet of systems resembling today's internet. In addition, Tomlinson endorsed the "@" symbol in email addresses. Years later, Gary Thuerk, a Marketing Manager at Digital Equipment Corporation sent the first commercial email to a list of email addresses, and "Email marketing" was born because of this. Email marketing is about buyers' interest and getting them to open emails, but that is not enough. Email marketing also motivates buyers to take additional actions. It is the most profitable direct marketing channel with an average return on investment of $\$ 42$ for every $\$ 1$ spent. We are littered with email marketing campaigns these days, and much of it still feels spammy, but there's no denying the power of a well-crafted message to influence your customers. Some buyers interested in your product typically purchase, less than 20 percent of prospective buyers tend to purchase (An, 2016). Generally, out of the 100 people interested in your product, only 20 people will be ready to purchase products from you. Besides, a study by MarketingSherpa found that 60 percent of customers opted to receive brand emails to track promotions and deals. Only 20 percent of customers use the social media platform to communicate. Email marketing is an extremely effective marketing tool that allows you to connect with your target audience to promote your brand and increase sales. Emails can be used to sell products, share news, reduce cart abandonment, or tell a story. According to Gadsby 2018 data, email is still the most effective digital technique. It also outperforms social media, search engine optimization (SEO), and affiliate marketing. Most people use email, which comprises about 85 percent of adult internet users in the United States (Kunst, 2019). That outperforms search engines by 15 percent and social media by 22 percent - In an industry that gets excited about single-digit conversion rate improvements, these are very significant figures.

\section{Guest Blogging}

It is an effective tactic that benefits a company's inbound marketing efforts in multiple ways. It not only enables you to assess authority as a thought leader in the industry, but it is also an effective way to improve the performance of your website and get your content ranked on search engines like Google. Finding websites that accept guest blog authors can take a significant amount of time and effort. Furthermore, you must seek out the appropriate opportunities to ensure that your time is well spent. According to Neil Patel's article, embracing guest blogging reaped significant benefits. He provides numerous examples of "Why Guest Blogging Is the Best Inbound Marketing Strategy." For example, a single guest post he wrote and published on Moz generated nearly 400 visitors (Patel, 2020). In the article, "Triple Your Traffic by Guest Blogging for Backlinks," guest blogger Joseph (2013) explains how one marketer was able to increase search traffic by 340 percent over 100,000 visitors 
in one year. Bryan was able to get his blog off to a good start due to guest blogging. He now has a devoted following, and his most recent product launch generated $\$ 220,750$ in invoice sales. Keep in mind that it all started with a single guest post (Harris, 2015). Guest blogging allows you to be discovered on social media. Every time you publish a new article, you create content that people can share on social media platforms like Twitter, LinkedIn, Facebook, and Pinterest. This creates exposure for a company to a new audience that they may not be familiar with yet (Gynn, 2021).

Furthermore, guest blogs should be used to educate readers rather than to promote products or services. If the topic is relevant to a product or service, there is no reason not to include it in the blog. However, there is a significant difference between selling and providing practical, actionable information to readers (Burnam, 2019).

\section{Search Engine Optimization (SEO), in Google}

SEO (Search Engine Optimization) refers to optimizing websites to obtain the first page ranking of search engines. This place is focused on the most popular search engine, Google, because it is the most widely recognized platform. According to search engine market share (Statcounter Global Stats, 2021), the traffic of Google from June 2020 to June 2020 draws ahead of other search engines (Figure 1). Google usually ranks websites that have the potential to attract visitors on the top of the search page. This is the process of making websites of better quality and getting organic traffic that leads to more opportunities to sell products without buying ads. An essential factor of SEO for e-commerce is determining the keywords to help people locate products or services. The more exposure of your pages in search results, the more you attract consumers to your website.

Furthermore, there are factors such as onsite content, outreach, blog, and backlink. These factors directly affect Google Search ranking. Google uses an algorithm to evaluate websites and content displayed when a user searches on Google. These algorithms have developed to be incredibly sophisticated by considering the rankings of unique search results each time.

There are hundreds of Google Algorithms, and it is very detailed, but the latest algorithm update directly relates to the Page Experience Signal that may affect SEO ranking. SEO ranking consists of mobile-friendliness, safebrowsing, HTTPS-security, intrusive interstitial guidelines, and Core Web Vitals, which are metrics used to measure user experience divided into Largest Contentful Paint (LCP); Loading speed on the website; First Input Delay (FID); Responsive speed to clicks on a web page, Cumulative Layout Shift (CLS); Stability of website design. The page experience update will be spread to all users gradually, expecting to achieve $100 \%$ by the end of August 2021.

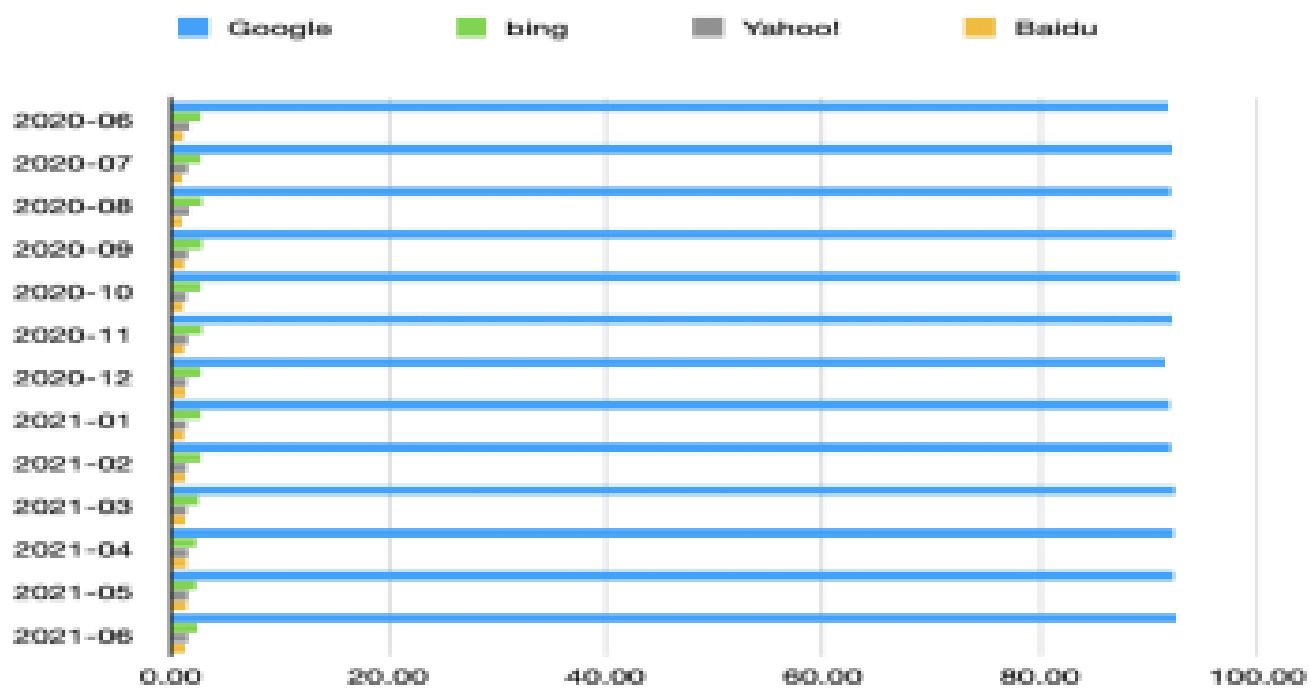

Figure 1. Search Engine Market Share Worldwide June 2020-June 2021

Source: Statcounter Global Stats. 


\section{Word of Mouth Considerations}

Purchase decisions are heavily influenced by word of mouth. Nowadays, when information is abundant, your brain is bombarded with over a million different pieces of information. Sometimes what we hear are from nearby individuals what people think about items and services or other methods to discover information on the internet. Furthermore, people tend to seek information before purchasing with very few opportunities to search and click to buy immediately, even before search engines. So, "content" is critical to helping people know, understand, and follow, ultimately leading to commitment. Posting a question in the general forum has a significant impact on the purchase choice. Even if they intend to promote through multiple online channels successfully, product or service reviews influence 93 percent of people's purchase decisions.This doesn't always mean that you can generate conversions or a customer base if brand reviews or posts are negative. In addition, SEO experts believe that positive evaluations improve your chances of reaching the top of the search results, up to 10 percent of the pages on search engines. Word of mouth is the most straightforward approach to boost the appeal of a successful brand. We need to be concerned about feedback from consumers because it has an impact on brand image. We can search for consumer feedback on the internet. To properly plan and modify the communication strategy, a report from Bright Local reveals that 88 percent trust consumer reviews as much as a recommendation from a close friend.

\section{Influencer Marketing}

Influencers can drive brands to become popular in the marketplace and generate reach as much as other strategies. Influencers are necessary for your business if a brand wants to expand the market to increase its spread as much as possible. For online marketing, influencers are a tool to help your brand get better known and drive more traffic. Their online reputations can benefit your brands by becoming more well-known. Someone who has a lot of followers through various social channels is like a Key Opinion Leader (KOL), a leader or expert in a field. This can create influence and credibility to influence your followers. This influencer promotes your product by placing hyperlinks on their web pages to encourage followers to click on the link to your brand page. It is causing these followers curiosity and wants to emulate the people they admire. After all, influencers influence the decisions of the customer. And brand marketers need to know accurately who their target audience is. Know your customers' age or other relevant information to select the right influencers on the right platform.

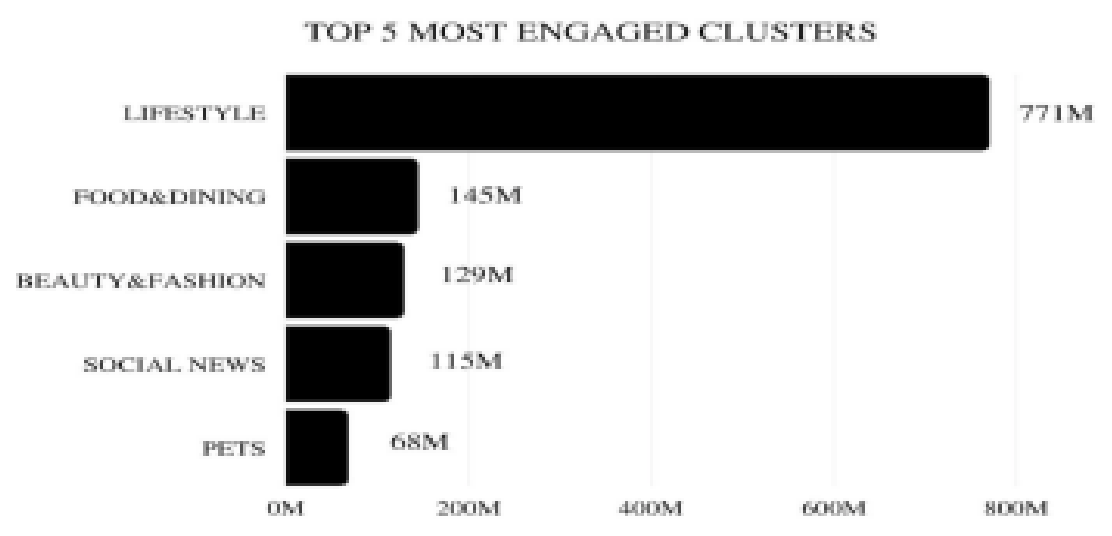

Figure 2. Calculated by total engagements in April-June 2019

Source: Wisesight.

Based on the 2019 statistics of Thailand Influencers from Wisesight, the fastest-growing influencer statistic is Food and Pet Influencers because this affects our feelings and emotions (Figure 2). As per the social media influencer market stats and research for 2021 (Insider Intelligence, 2021), the \#1 prime influencer marketing platform will remain Instagram (79\%), followed by Facebook (46\%), YouTube (36\%), and Twitter (24\%). According to Hootsuite statistics, 500 million people use IG Stories daily, and 58\% said they are interested in a brand or product after seeing it in IG Stories. Also, $50 \%$ often visit a website to buy a product after watching IG Stories. Stories are an important channel for brands (Newberry, 2021). The difference between stories and regular posts on the feed is that if a micro-influencer has 10,000 followers or more, their IG stories will include links. 
People interested in the product can swipe up the screen to lead to the store's landing page, which gives the opportunity to sell more products.

\section{Special Promotions to Attract Customers by Rewards}

Online stores that sell their products through multiple channels and aim to boost website traffic may provide a special discount for purchases made through their website. Alternatively, a firm can offer discount vouchers to existing customers who recommend friends to your website. It not only promotes the website but also builds a satisfying relationship with site visitors. The reward of playing a game, subscribing, or registering is a marketing strategy that consistently produces positive outcomes. In addition, the number of people who engage with the online platform will grow. Brands can also increase their followers and gather information from customers through this channel. Easypromosapp statistics show that 94 percent of people who receive messages click to join or follow right away, and 62 percent of those who see the message share a promotion or suggest a friend who can alert you to attractive bargains.

\section{Podcasts Creating}

In 2021, podcasts were rated high on the list because in leisure time, people bring them or link to them to listen to their topics of interests. If your brand can create podcasts related to your products and services or invite speakers to discuss your brand's industry, it will create an excellent reach. According to Edison Research, podcast listening statistics of the new generation has grown by 175 percent in the past five years, or about 90 million listeners each month. The report of STEPS Academy said that there are also podcasts on digital marketing topics. In addition, providing knowledge and good content is also an inspiration to the listeners.

\section{Discussion}

This study aimed to identify the strategy of expanding the engagement for e-commerce. We tried to answer the research question, how to increase traffic on websites? There is a correlation between e-commerce business and developing the website's visibility. Various methods can be utilized to increase website traffic to achieve the goal of increasing engagement. According to the study results, the use of social commerce and SEO are the most effective. Online shopping is not new for most modern or tech-savvy customers, but the coronavirus pandemic led to the popularity of social commerce. Social commerce is a platform that meets the needs of consumers today. It can also establish relationships between buyers and sellers in real-time. This is the main point that makes various businesses participate in social commerce. The data contributes to a clearer understanding of online shopping and has the potential to become a normal behavior even though the coronavirus pandemic will be ending. Search Engine Optimization is an essential instrument for those who operate a website. SEO refers to the process of optimizing a website as it appears in the searches of the most popular search engines, such as Google. Getting a website's SEO ranking to the top of Google is one of the most important things any web developer needs. When Google presents the website as the top search, it will attract more visitors, thereby increasing the number of website viewers. Overall, the research findings suggest that the strategies mentioned above have a few contrasts. Using a social commerce strategy is dwelling on external platforms and focusing on quick response. Meanwhile, SEO focuses on establishing websites and being found at the top of the search results page. In terms of immediacy and convenience, social commerce fulfills the demand of customers. And in terms of being well-known and stable, SEO is the optimal choice for business. By the way, both strategies can be applied simultaneously. Companies should use these strategies to their business appropriately.

Expanding the engagement for e-commerce should encompass the following: Responsive Website, Video Content Marketing, Native advertising, Social Commerce, Email Marketing, Guest blogging, SEO, Word of mouth, Influencer Marketing, Attracting Customers by Rewards, and Podcasts Creating. In addition, website design should include the internal search feature and links to discover and use forms, and sign-ups should only require important information and offer helpful feedback. The most significant element in developing an e-commerce firm is good website usability. Customers are more likely to stay on an e-commerce website and become connected with the company's brand when it is easy to use, which helps a business achieve its goals. Nevertheless, customer behavior tends to change from time to time. The company should develop a communication strategy 
with customers according to trends. It is important to note that you should always have clear goals and objectives for your website, which can include things like.

- $\quad$ Use the e-commerce or website to expand business.

- $\quad$ Expand sales outside local area.

- $\quad$ Generate a certain number of sales per month to existing clients.

- $\quad$ Reduce direct marketing expenses from flyer distribution and promo catalogues.

- $\quad$ Enhance customer service, etc.

\section{Conclusions}

Overall, we have discussed that e-commerce is the process of buying and/or selling products or services using modern technology in today's cyberspace. You can use e-commerce to promote your brand, get more customers, increase sales, provide better service, and to offer after sale services. A key objective of any e-commerce business or their website should be to effectively engage existing and future clients.

The web traffic strategies discussed in this paper can help your company's website add more value. Applying these strategies allows you to focus on limited resources and skills to achieve effective online marketing and future e-commerce consumer interaction. The proven records of various experienced professionals on digital and social media marketing issues from diverse perspectives in this research enable compelling explanations of significant matters on critical topics. To conclude, the increased ranking of the website helps you build trust, which will increase the chances of becoming a well-known website and engage many users for sustainable competitiveness in today's global world of business.

Funding: self-funded.

Author contribution: Conceptualization: Jenjira Phomkamin, Chalita Pumpuang, Pattarawan Potijak, Supaporn Sangngam, and Issariya Ketprasit. Data curation: Jenjira Phomkamin, Chalita Pumpuang, Pattarawan Potijak, Supaporn Sangngam, and Issariya Ketprasit. Formal analysis: Jenjira Phomkamin, Chalita Pumpuang, Pattarawan Potijak, Spaporn Sangngam, Bahaudin G. Mujtaba, and Issariya Ketprasit. Funding acquisition: not applicable. Investigation: Jenjira Phomkamin, Chalita Pumpuang, Pattarawan Potijak, Supaporn Sangngam, Bahaudin G. Mujtaba, and Issariya Ketprasit. Methodology: Jenjira Phomkamin, Chalita Pumpuang, Pattarawan Potijak, Supaporn Sangngam, Bahaudin G. Mujtaba, and Issariya Ketprasit. Project administration: Jenjira Phomkamin, Chalita Pumpuang, Pattarawan Potijak, Supaporn Sangngam, and Issariya Ketprasit. Resources: not applicable. Software: not applicable. Supervision: Bahaudin G. Mujtaba. Validation: Jenjira Phomkamin, Chalita Pumpuang, Pattarawan Potijak, Supaporn Sangngam, and Issariya Ketprasit. Visualization: Jenjira Phomkamin, Chalita Pumpuang, Pattarawan Potijak, Supaporn Sangngam, and Issariya Ketprasit. Writing - original draft: Jenjira Phomkamin, Chalita Pumpuang, Pattarawan Potijak, Supaporn Sangngam, and Issariya Ketprasit. Writing: review \& editing, Jenjira Phomkamin and Bahaudin G. Mujtaba.

\section{Authors' Biographies}

Jenjira Phomkamin is a Bachelor of Arts in English student at the Institute of International Studies, Ramkhamhaeng University. She was born and raised in Phetchabun, Thailand. Her goal is to develop her parents' business. To help to reach the goal, she is looking to further her skills in business administration.

Chalita Pumpuang was born and raised in Samutprakarn, Thailand. She has finished her secondary school at Bangkok Witthaya Foundation School. She was a high school volleyball player at the time and participated in numerous outdoor races. She currently resides in Samutprakarn and is pursuing a Bachelor of Arts in English at the Institute of International Studies in Ramkhamhaeng University.

Pattarawan Potijak is a current Bachelor of Arts in English student at the Institute of International Studies. Meanwhile, she is studying for a second degree in Bachelor of Accountancy at Ramkhamhaeng University.

Supaporn Sangngam is a Bachelor of Arts in English student at the Institute of International Studies, Ramkhamhaeng University. She was born and raised in Ranong, Thailand, and she relocated to Bangkok, 
Thailand, for her study goal. She can speak Thai, English, and Myanmar.

Issariya Ketprasit was born and raised in Bangkok, Thailand. She has finished her secondary school at Bangkok Witthaya Foundation School. She is currently in Bachelor of Arts in English at the Institute of International Studies at Ramkhamhaeng University.

Bahaudin G. Mujtaba is Professor of Human Resources at Nova Southeastern University in Ft. Lauderdale, Florida. Bahaudin is the author and co-author of several professional and academic books dealing with diversity, ethics, and management, as well as numerous academic journal articles. During the past thirty years, he has had the pleasure of working with human resource professionals in the United States, Brazil, Bahamas, Afghanistan, Pakistan, St. Lucia, Grenada, Malaysia, Vietnam, Japan, China, India, Thailand, and Jamaica. This diverse exposure has provided him many insights in ethics, culture, and management from the perspectives of different firms, people groups, and countries.

\section{References}

1. An, M. (2020, October 29). Buyers Speak Out: How Sales Needs to Evolve. HubSpot Blog. [Link].

2. A.S. Ajina (2019). The perceived value of social media marketing: An empirical study of online wordof-mouth in Saudi Arabian context. Entrepreneurship and Sustainability Issues, 6 (3), 1512-1527. [Link].

3. Authorize.Net (2012). E-commerce: Getting Started Guide. Authorize.Net: San Francisco. [Link].

4. Basics of Branding. Mailchimp. (n.d.). [Link].

5. Bessemer E-Commerce Laws (2010). Bessemer's Top 10 Laws of E-Commerce. Bessemer Venture Partners: New York. [Link].

6. BigCommerce. (2021, July 17). Effective social media use in ecommerce marketing. [Link].

7. Chevalier, S. (2021, July 7). Mobile shopping penetration 2020. Statista. [Link].

8. Creative, S. (n.d.). What is Video Content Marketing? Overview \& Resources. Skeleton. [Link].

9. Feldman, B. (2021, May 8). Where Does Native Advertising Stand in 2019? TaboolaBlog. [Link].

10. Frankenfield, J. (2021, May 19). Search Engine Optimization (SEO). Investopedia. [Link]. Google. (n.d.). Google. [Link].

11. Google. (n.d.). Google. [Link].

12. Google. (n.d.). Google. [Link].

13. Grover, P. Kar, A.K., Dwivedi, Y.K. and Janssen, M. (2019). Polarization and acculturation in US Election 2016 outcomes-can twitter analytics predict changes in voting preferences. Technological Forecasting and Social Change, 145, 438-460. [Link].

14. Guest Blogging Strategy Guide. Content Marketing Institute. (2021, June 29). [Link].

15. Guest Blogger Guest Blogger Joseph (2013). Triple Your Traffic by Guest Blogging for Backlinks. [Link].

16. Hughes, J., \& About John Hughes. John is a blogging addict (2021, June 8). How to Drive High-Quality

Traffic to Your Affiliate Marketing Site (3 Ways). Easy Affiliate. [Link].

17. Intelligence, I. (2021, January 6). Influencer marketing: Social media influencer market stats and research for 2021. Business Insider. [Link].

18. Janaway, M., Chaffey, D., \& Dormer, L. (2019, February 12). Email marketing is still worth taking seriously in 2018. Smart Insights. [Link].

19. KnowBe4.com (2021). Security training awareness workshop online. Nova Southeastern University. [Link].

20. Kunst, A. (2019, September 3). Daily U.S. online activities 2017. Statista. [Link].

21. Kutz, Martin (2016). Introduction to E-Commerce: Combining Business and Information Technology. Bookboon eLibrary. [Link].

22. Lipsman, A. (2021, February 3). Social Commerce 2021. Insider Intelligence. [Link].

23. Listener (2017) Attenboroughsays:, T., Deansays:, B., Oarsays:, N., Kirksays:, L., Davissays:, D., Singhsays:, N., Ledouxsays:, D., Getersays:, T., Hainstocksays:, J., Dassays:, D., Adriansays: Makarasays:, C., Beckwithsays:, B., Tamponsays:, V., Stevesays: Malonesays:, J., Jacksays: Josssays: Robbinsays: ... Petersays: (2020, December 24). 27 Ways to Increase Traffic to Your Website. Backlinko. [Link].

24. Mohsin, M. (2021, July 15). 10 Video Marketing Statistics You Should Know for 2021[Infographic]. 
Oberlo. [Link].

25. MalwareFox (May 19, 2020). What is Spear Phishing| Difference from Phishing and Whaling. [Link].

26. Native Advertising - How it works. Outbrain. (n.d.). [Link].

27. Ong, S. Q. (2021, June 29). 11 Proven Ways to Drive Traffic to Your Website. SEO Blog byAhrefs. [Link].

28. Ontario E-Commerce (2013). E-Commerce: Purchasing and Selling Online. Part of "E-Business Toolkit". Queen's Printer for Ontario: Canada. [Link].

29. Pacy Media. (2021, June 21). Google algorithm อัพเดท 2021 กับ 7 สิ่งที่กระทบ seo ranking. Pacy Media. [Link].

30. Patel, Neil (2021, March 18). Why Guest Blogging is The Best Inbound Marketing Strategy (A Data Driven Answer). [Link].

31. Phaneuf, A. (2021, May 18). Social Commerce 2021: Social media and ecommerce convergence trends brings growth opportunity for brands. Business Insider. Search engine market share worldwide. StatCounter Global Stats. (n.d.). [Link].

32. Schneider, Gary P. (2013). Electronic Commerce, $10^{\text {th }}$ Edition. Cengage Learning: United States. [Link]. 33. Search Engine Optimization. Optimizely. (n.d.). [Link].

34. SEO คืออะไร? ค ำตอบของคนท ำธุรกิจ เนื้อหำครบ จบในที่เดียว! Primal Digital Agency. (2020, December 8). [Link].

35. Smith, G. (2007, December 3). Unsung innovators: Gary Thuerk, the father of spam.Computerworld. [Link].

36. Shim, J. K. (2010). The International Handbook of Electronic Commerce. Global Professional Publishing: USA. [Link].

37. Swatman, R. (2015, August 19). 1971: First Ever Email. Guinness World Records. [Link].

38. Tankovska, H. (2021, June 30). Daily social media usage worldwide. Statista. [Link].

39. The BigCommerce Blog (2021, April 12). Social Commerce: How Social Shopping Can Drive Sales (2018). [Link].

40. The Covey Agency. (2018, February 2). How To Engage Customers On Social Media: Covey Digital Blog. [Link].

41. Video Marketing Statistics 2021 (Brand New Data). Wyzowl. (n.d.). [Link].

42. Watson, R.T, Berthon, P., Pitt, L.F. and Zinkhan, G. M. (2008 or latest edition). Electronic Commerce: The Strategic Perspective (2 ${ }^{\text {nd }}$ edition). Global Text Project: Switzerland. [Link].

43. What is Guest Blogging? And Why it's Important for Your Business. New Breed. (n.d.). [Link].

44. What Is SEO / Search Engine Optimization? Search Engine Land. (2021, June 14). [Link].

45. Wyman, Oliver (2018). From the Speed of Sound to the Speed of Light: Organizing for Success in China's E-Commerce Market. Marsh \& McLennan Companies: New York, NY. [Link].

46. Ways to Find Guest Blogging Opportunities for Your Business. New Breed. (n.d.). [Link].

47. Ways to Increase Website Traffic. Mailchimp. (n.d.). [Link].

48. Proven Ways to Increase Traffic to Your Website. Mike Gingerich. (2020, October 23). [Link].

49. Ways to Increase Traffic to Your Website. WordStream. (n.d.). [Link].

50. Instagram statistics that matter to marketers in 2021. Social Media Marketing \& Management Dashboard. (2021, February 3). [Link].

51. N. (2020, June 1). Native Advertising. UNBOXBKK. [Link]. 